\title{
ABKURZUNGSVERZEICHNIS
}

\section{der hauptsächlich benutzten Literatur}

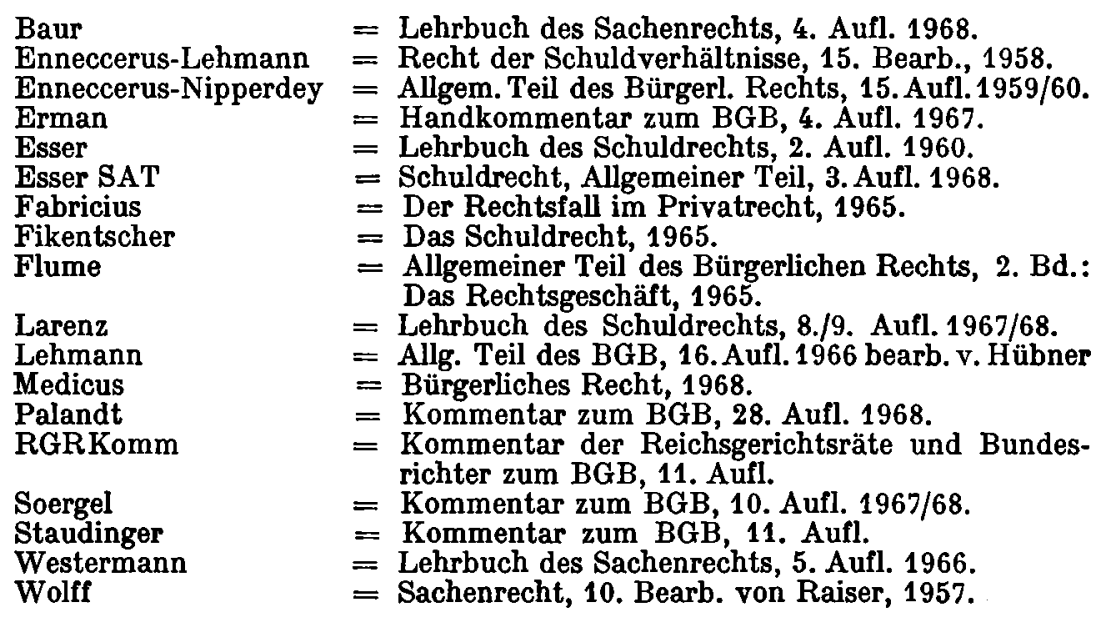

Hinweise auf weitere Anleitungsbücher des Verfassers

Familienrecht

Gutachten

Handelsrecht

Hausarbeit

Referendarklausur

AcP

BGH

JR

JuS

JW

JZ

Lind-Möhr.

\section{NJW \\ OLG \\ RG}

RGSt.
= Familien- und Erbrecht, Schaeffers-Rechtsfälle Bd. 4, 31.-33. Tsd., 1968 bearbeitet von Berg.

$=$ Gutachten und Urteil, Schaeffers-Rechtsfälle Bd. 12, 23.-26. Tsd. 1967.

$=$ Handelsr. einschl. Gesellschafts- u. Wertpapierrecht, Scheaffers-Rechtsfälle Bd.5,16.—19.Tsd. 1967.

$=$ Die Hausarbeit im Referendarexamen, SchaeffersRechtsfälle Bd. 10, 4.-6. Tsd. 1965.

$=$ Die Klausurarbeitim Referendarexamen,SchaeffersRechtsfälle Bd. 11, 8.—10. Tsd. 1964.

\section{Sonstige Abkürzungen}

$=$ Archiv für civilistische Praxis.

$=$ Entscheidungen des Bundesgerichtshofes in Zivilsachen.

$=$ Juristische Rundschau.

$=$ Juristische Schulung.

$=$ Juristische Wochenschrift.

$=$ Juristenzeitung.

$=$ Das Nachschlagewerk des Bundesgerichtshofs, herausgegeben von Lindenmaier $u$. Möhring.

$=$ Neue Juristische Wochenschrift.

= Sammlung der Rechtspr. der Oberlandesgerichte.

$=$ Entscheidungen des Reichsgerichts in Zivilsachen.

$=$ Entscheidungen des Reichsgerichts in Strafsachen. 
Erster Teil

Übungen für Anfänger 
